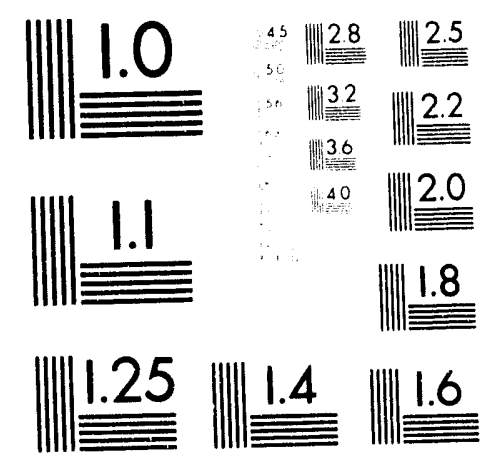



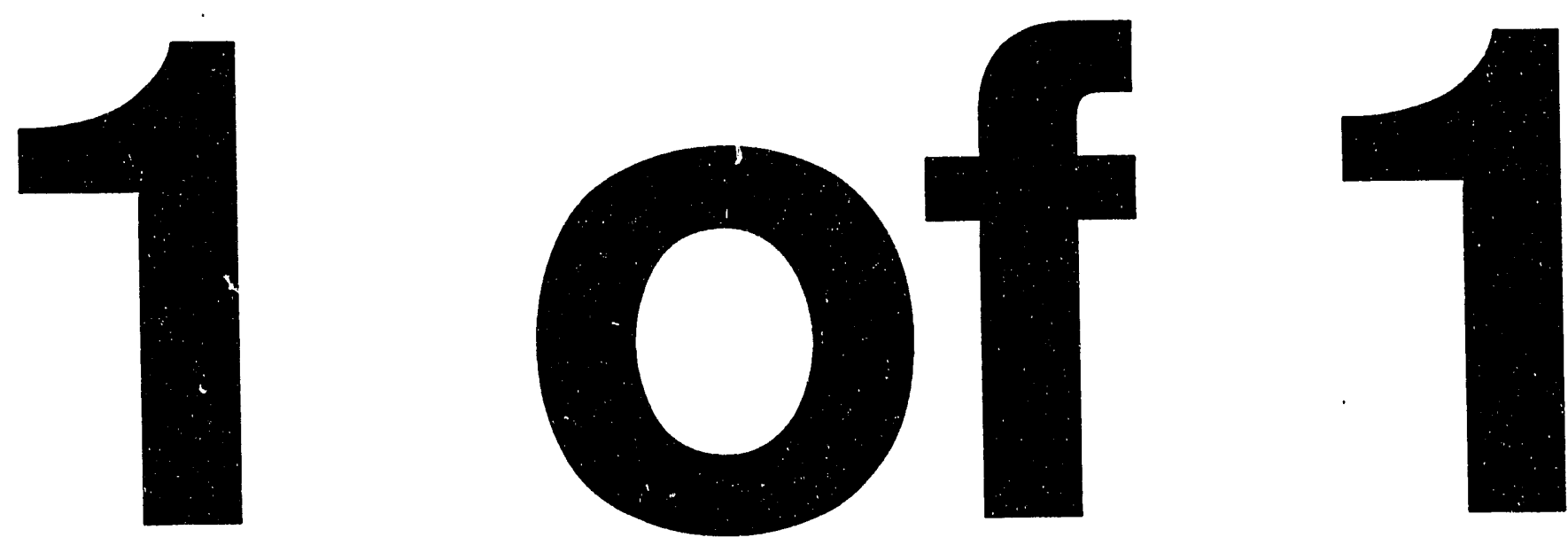


\title{
EXPERIMENT HFR-B1: A PRELIMINARY ANALYSIS OF THE WATER-VAPOR INJECTION EXPERIMENTS IN CAPSULE 3
}

\author{
B. F. Myers \\ Oak Ridge National Laboratory \\ Oak Ridge, Tennessee, 378316
}

\begin{abstract}
A preliminary analysis of selected aspects of the water-vapor injection tests in capsule 3 of experiment HFR-B1 is presented. The release of fission gas stored in bubbles and the diffusive release of fission-gas atoms are distinguished. The dependence of the release of stored fission gas $\left({ }^{\mathrm{BS}} \mathrm{Kr}\right)$ on water-vapor pressure, $\mathrm{P}\left(\mathrm{H}_{2} \mathrm{O}\right)$, and temperature were established taking into account the contributing mechanisms of gaseous release, the effect of graphite hydrolysis, and the requirement of consistency with experiment HRB-17 in which similar water-vapor injection tests were conducted. The dependence on $\mathrm{P}\left(\mathrm{H}_{2} \mathrm{O}\right)$ becomes weaker as temperatures increase above $770^{\circ} \mathrm{C}$; the activation energy for release of stored-fission gas is $393 \mathrm{~kJ} / \mathrm{mol}$. Isorelease curves for the pressure-temperature plane were deduced from a derived functional relation. The storedfission gas releases as a function of $\mathrm{P}\left(\mathrm{H}_{2} \mathrm{O}\right)$ at a common $t \mathrm{r}$.nperature for experiments HFR-B1 and HRB-17 differ by a factor of 4; this discrepancy could be attributed to the differences in fission-rate density and neutron flux between the two experiments. Diffusive release of fission gas occurred during and after the release of stored gas. The ratio of diffusive release during water-vapor injection to that prior to injection varied in contrast to the results from HRB-17. The variation was attributed to the practice of injecting water vapor into HFR-B1 before sintering of the fuel, hydrolyzed in the previous test, was completed. The derived activation energy for diffusive release is $23.6 \mathrm{~kJ} / \mathrm{mol}$.
\end{abstract}

\section{INTRODUCTION}

A preliminary analysis of the response of uranium oxycarbide (UCO) fuel to water vapor addition in capsule 3 of experiment HFR-B1 (HFR-B1/3) has been conducted. The analysis provides an early indication of the behavior of fission gas release under a wider range of water-vapor pressures and of temperatures than heretofore studied.

'Research sponsored by the Office of New Production Reactors, U.S. Department of Energy, under contract DE-AC05-84OR21400 with Martin Marietta Energy Systems, Inc.

DISCLAIMER

This report was prepared as an account of work sponsored by an agency of the United States Government. Neither the United States Government nor any agency thereof, nor any of their employees, makes any warranty, express or implied, or assumes any legal liability or responsibility for the accuracy, completeness, or usefulness of any information, apparatus, product, or process disclosed, or represents that its use would not infringe privately owned rights. Reference herein to any specific commercial product, process, or service by trade name, trademark, manufacturer, or otherwise does not necessarily constitute or imply its endorsement, recommendation, oi favoring by the United States Government or any agency thereof. The views and opinions of authors expressed herein do not necessarily state or reflect those of the United States Government or any agency thereof. 
The results of an analysis of a similar experiment in HRB-17 (Myers, 1992) were the basis for the analysis of HFR-BI/3. These results involved, with regard to the time profiles of fission-gas release, (1) an initial rapid release and (2) a subsequent steady release, during water-vapor injection, and (3) a decline in release following termination of water-vapor injection. In event 1 , stored gas is being released along with the diffusional release normally encountered from fuel; in event 2 , only diffusional release of fission gas is occurring, and in event 3 , the diffusional release is declining as the fuel is sintering and densifying.

In experiments HRB-17 and HFR-B1, water vapor was injected into capsules containing fuel compacts with designed-to-fail (dif) and normally configured fuel particles; ihe dif particles constituted 2.9 and $8.9 \%$ of all fuel particles, respectively. The dif particles, composed of a UCO kernel surrounded only by a thin layer of pyrocarbon, failed as a result of fission-fragment, induced damage shortly after the beginning of irradiation (Myers, 1992). In this manner, a known source of fission products was created. In HFR-B1, the temperatures were between 820 and $1040^{\circ} \mathrm{C}$ and in HRB-17, between 755 and $780^{\circ} \mathrm{C}$; correspondingly, the water-vapor pressures were between 3 and $1050 \mathrm{~Pa}$ in HFR-B1 and 20 and $199 \mathrm{~Pa}$ in HRB-17.

in analyzing the release of ${ }^{85 \mathrm{~m}} \mathrm{Kr}$, the following criteria were adopted.

(1) The results of HRB-17 and HFR-B1 should be consistent.

(2) The fractional release of stored-fission gas is independent of the gaseous element or its isotopes.

The principle of consistency is applicable because the phenomena involved are the same. The independence of the stored-gas release on isotope is expected and was observed in the HRB-17 experiment.

\section{DATA}

Only the ${ }^{85 \mathrm{~m}} \mathrm{Kr}$ data were used in this preliminary analysis. The data available were on graphs of $R / B$ versus time which included temperatures and water-vapor pressures (Conrad, Burnette and Timke, 1990). The R/B data were digitized.

\section{PRELIMINARY ANALYSIS}

Event 1 , the release of stored-fission gas, and event 2, the diffusive release of fission gas, are addressed in the preliminary analysis.

\subsection{THE RELEASE OF STORED-FISSION GAS}

For the analysis of the release of stored-fission gas, the quantity released, the partial pressure of water vapor, the temperature and the neutron flux and fluence are needed.

\subsubsection{The quantity of stored-fission gas released}

The analysis of experiment HRB-17 revealed that stored-fission gas was released just after the addition of water vapor to the capsule containing the fucl compact. A concomitant diffusive release 
of fission gas was evident by 4 iomparison of the prehydrolysis release with that observed after the cessation of the release of stored gas. To evaluate the release of stored-fission gas as a fraction of the inventory, the following relation (Myers, 1992; see Appendix A) was and is used:

$$
f=\Sigma_{1}\left[(R / B)_{s d}-(R / B)_{d}\right\}_{i} \Delta l_{i} \lambda
$$

where

$$
\begin{aligned}
f= & \text { the fraction of the inventory released as stored-fission gas, } \\
(R / B)_{j}= & \text { the } R / B \text { value for the release of stored-fission gas plus diffusive release }(j=s d) \\
& \text { or for the diffusive release only }(j=d), \\
\Delta t_{i}= & \text { time interval during which the } i-t h \text { difference in } R / B \text { is taken io be constant }(s), \\
\lambda= & \text { decay constant }\left(\mathrm{s}^{-1}\right) .
\end{aligned}
$$

The evaluation of Eq. (1) requires knowledge of $(R / B)_{s d}$ and $(R / B)_{d}$. The former is derived from release measurements after the start of water-vapor injection and the latter is based on measurements of (1) the prehydrolysis fission-gas release, (2) the fission-gas release after the cessation of the release of stored-fission gas, and (3) a curve connecting these two subsets of measurements. The curve is based on the HRB-17 experiment and can be taken as linear in time to a sufficiently good approximation. The profiles of $(R / B)_{s d}$ and $(R / B)_{d}$ from the water-vapor injection in HFR-B1 cycle 89.06 at $820^{\circ} \mathrm{C}$ are shown in Fig. 1 as an example.

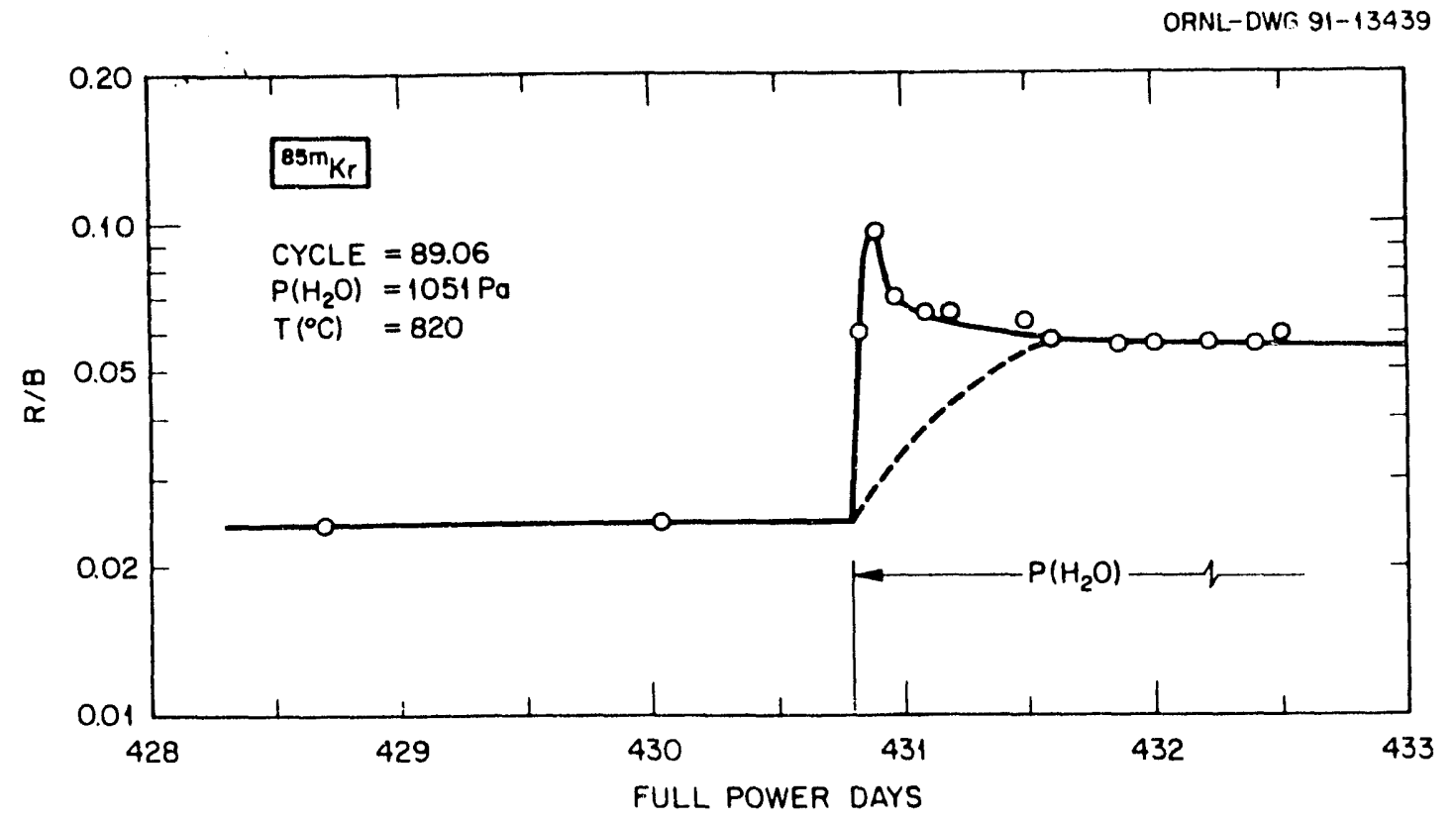

Fig. 1. Decomposition of the $R / B$ profile after the beginning of water-vapor injection into contributions from the release of stored-fission gas and from diffusive relcase. Note: The contribution of stored gas to release occurs between 430.8 and $431.6 \mathrm{~d}$. In this time interval, the upper curve represents (R/B) sd, the lower curve, (R/B) $)_{d}$ See Eq. (1). 


\subsubsection{The nartial pressure of water vapor}

The partial pressure of water vapor added to the capsule was grea'er than the partial pressure reaching the surfaces of the fucl compacts. As indicated in Fig. 2a, the water vapor had to pass through the graphite body in which the fuel compacts were contained and in so doing, reacted with the graphite. The extent of reaction was small at the lowest temperature of the experiments, $820^{\circ} \mathrm{C}$ and was large at the highest temperature, $1040^{\circ} \mathrm{C}$. In experiment HRB-17, in contrast, the water vapor was added so as to pass directly over the surfaces of the fuel compacts without having to pass through the graphite body as shown in Fig. $2 b$.

The partial pressure of water vapor at the surfaces of the fucl compact was calculated (Richards, 1990, private communication) using the code REACT. The code REACT yields a solution of species conservation equations involving diffusion and reaction in a porous medium (graphite) and of an equation for apparent graphite density. The conservation equations are independent of pore structure, use volume averaged dependent variables, can account for convective transport, and the effect of voidfraction gradients on the rate of the $\mathrm{H}_{2} \mathrm{O}$-graphite reaction (Richards, 1990).

\subsubsection{The denendence of release of stored-fission gas on the water-vapor pressure and temperature}

The values of the fractional release of stored-fission gas, the water-vapor pressures at the surfaces of the fuel compacts, and the temperatures are presented in Table 1 for the eight experiments included in the analysis.

The dependence of the release of stored-fission gas on both the vapor pressure of water and on the temperature has been previously established (Myers, 1992; Myers and Morrissey, 1978). In experiment HRB-17 at constant temperature, the release of stored-fission gas as a fraction of the inventory was found to be dependent on $P^{n}$, the partial pressure of water vapor to the power $n$ with $\mathrm{n}=1.9$ at $770^{\circ} \mathrm{C}$. In postirradiation heating experiments (Myers and Morrissey, 1978) in the absence of water vapor, the release of stored-fission gas was found to become significant at temperatures $z 1400^{\circ} \mathrm{C}$ for $\mathrm{UC}_{2}$ and $\mathrm{UCO}$. These results imply that the effect of water vapor on the release of stored-fission gas will dominate at relatively low temperatures, whereas, at increasingly higher temperatures the effect of water vapor will become less and less important. Furthermore, the possibility of synergism in regard to the effects of water vapor and temperature could lead to an enhanced importance of temperatures less than 1400$)^{\circ} \mathrm{C}$ in inducing the release of stored-fission gas. This possibility is consistent with the data of Table 1 as discussed below.

Table 1. The quantity of stored-fission gas released as a fraction of the inventory, the partial pressures of water vapor and the temperatures for experiment HFR-B1.

\begin{tabular}{lcccccc}
\hline $\begin{array}{l}\text { Inj. } \\
\text { No. }\end{array}$ & Cycle & $\mathrm{P}^{\circ}{ }_{\mathrm{H} 20}(\mathrm{~Pa})^{\mathrm{b}}$ & $\mathrm{P}_{\mathrm{H} 2 \mathrm{O}}(\mathrm{Pa})^{\mathrm{c}}$ & $\left.\mathrm{T}^{\circ}{ }^{\circ} \mathrm{C}\right)$ & $10^{4} / \mathrm{T}(\mathrm{K})$ & $\mathrm{f}^{\mathrm{d}}$ \\
\hline $15 \mathrm{a}$ & 89.06 & 1060 & 1050.0 & 820 & 9.149 & $7.6 \mathrm{E}-2$ \\
14 & 89.04 & 550 & 510.7 & 866 & 8.780 & $1.1 \mathrm{E}-1$ \\
13 & 89.02 & 250 & 184.2 & 915 & 8.418 & $2.9 \mathrm{E}-2$ \\
$12 \mathrm{~b}$ & 89.01 & 112 & 91.6 & 890 & 8.598 & $3.2 \mathrm{E}-2$ \\
11 & 88.10 & 123 & 12.2 & 1040 & 7.616 & $1.4 \mathrm{E}-2$ \\
5 & 88.01 & 90 & 56.5 & 925 & 8.347 & $4.1 \mathrm{E}-2$ \\
3 & 87.09 & 45 & 2.8 & 1040 & 7.616 & $5.7 \mathrm{E}-3$ \\
2 & 87.05 & 45 & 19.1 & 950 & 8.177 & $6.5 \mathrm{E}-3$
\end{tabular}

\footnotetext{
${ }^{\mathrm{a}}$ Inj. No. $=$ the sequential number of the water-vapor, injection test.

${ }^{\mathrm{b}} \mathrm{P}^{\circ}{ }_{\mathrm{H} 2 \mathrm{O}}=$ the partial pressure of added water vapor.

${ }^{\mathrm{c}} \mathrm{P}_{\mathrm{H} 2 \mathrm{O}}=$ the calculated partial pressure of water vapor at the fiel compact surfaces.

${ }^{d} f=$ the release of stored-fission gas as a fraction of the inventory.
} 


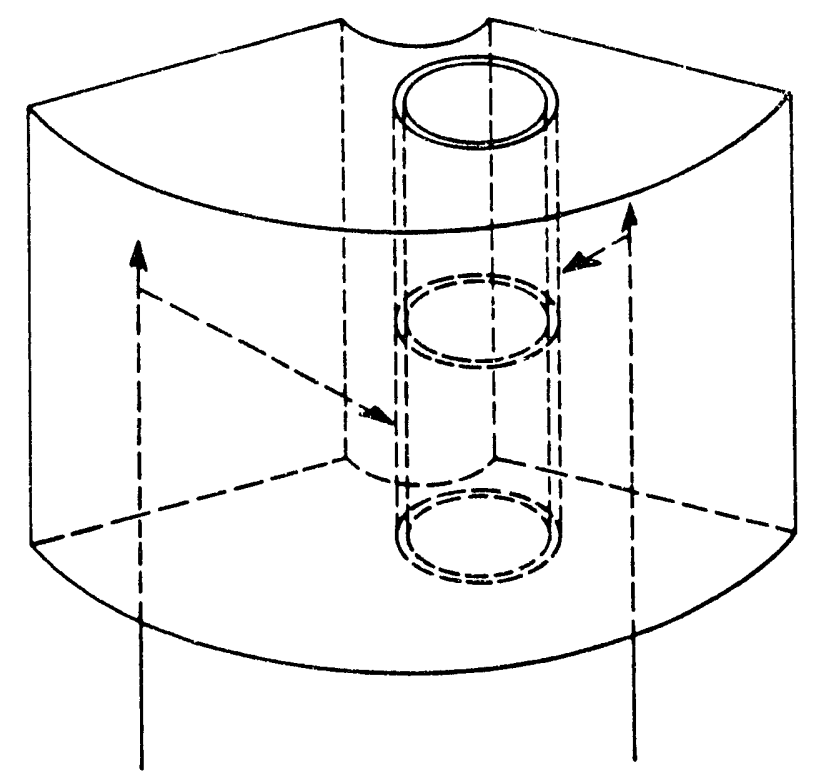

(a)

(b)

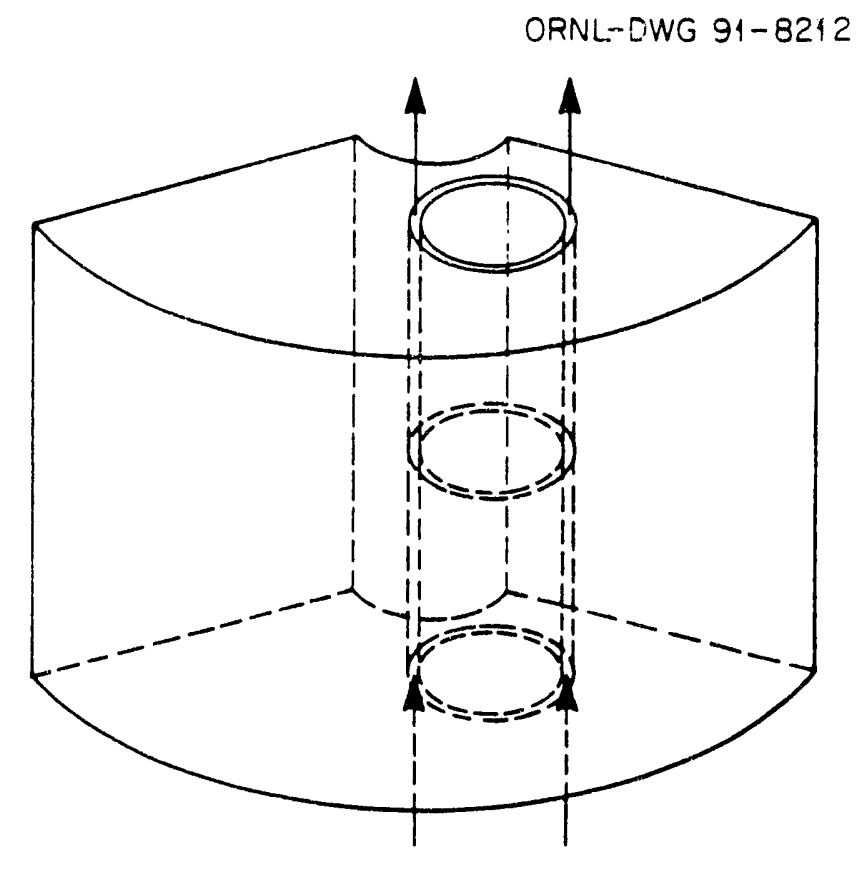

Fig. 2. The flov paths of carricr gas plus water vapor in the experimental configurations of experiments HRB-17, (a), and HFR-B1, (b). (a) flow of gas containing $\mathrm{H}_{2} \mathrm{O}$. (b) flow of gas containing $\mathrm{H}_{2} \mathrm{O}$ plus, at right angles, water-vapor flow through and reaction with graphite. 
The release of stored-fission gas as a fraction of the fission gas inventory has been, quite simply, represented by the empirical relation (Myers, 1992):

$$
f=K \cdot P^{n}
$$

where $f$ and $P^{n}$ have been defined above and $K$ is a constant. To incorporate the effects of temperature, Eq. (2) is generalized as follows:

$$
f=K \cdot P^{n(T)} e^{\cdot O / R T}
$$

where

$$
\begin{aligned}
\mathrm{n}(\mathrm{T}) & =\text { the temperature dependent exponent, } \\
\mathrm{Q} & =\text { the activation energy for release of stored gas }(\mathrm{J} / \mathrm{mol}), \\
\mathrm{R} & =\text { the gas constant }(8.314 \mathrm{~J} / \mathrm{mol} \cdot \mathrm{K}) \\
\mathrm{T} & =\text { the temp }, \text { rature }(\mathrm{K})
\end{aligned}
$$

Equation (3) is again an empirical expression as the temperature dependent exponent will be used to account for the declining contribution of the effects of water vapor to the release of stored-fission gas with increasing temperature. Limitations and restrictions on the use of Eq. (3) are discussed in Appendix B.

To apply Eq. (3) to the experimental results, the evaluation of $n(T)$ is first necessary. The simplest form of the temperature dependence of n, i.c.,

$$
\mathrm{n}=\alpha+B \mathrm{~T}^{-1}
$$

is chosen; $\alpha$ and $B$ are constants evaluated by using data from HRB-17 anc HFR-B1. In the analysis of HRB-17, $n=1.9$ at $770^{\circ} \mathrm{C}$. From the data of Table 1 at $1040^{\circ} \mathrm{C}, \mathrm{n}=0.60$ using Eq. (B-2) of Appendix B. Consequently, $\alpha=-4.353$ and $B=6503 \mathrm{~K}$ in the temperature range 770 to $1040^{\circ} \mathrm{C}$. Note that by using the value of $n$ determined in the analysis of HRB-17, the criterion of consistency, enunciated in the introduction, has been applicd.

To determine the constants $\mathrm{K}$ and $\mathrm{Q}$ of $\mathrm{Eq}$. (3), a lcast squares fit was made using the data of Table 1 and the values of $n$ calculated according to Eq. (4). The results are shown in Fig. 3 for a temperature of $770^{\circ} \mathrm{C}$." The derived values of $\mathrm{K}$ and $\mathrm{Q}$ are $2.13 \mathrm{E}+13$ and $392.9 \mathrm{~kJ} / \mathrm{mol}$. The activation energy for inducing the release of stored gas is quite large as might be expected on the basis of the structural changes required to breach the gas bubbles within the bulk fuel. The release of fission gas as a fraction of the inventory is then given by:

$$
\mathrm{f}=2.13 \cdot 10^{13} \mathrm{P}^{-4.353+6503 / \mathrm{T}} \exp \left\{-4.7257\left(10^{4} / \mathrm{T}\right)\right\}
$$

The straight line in Fig. 3 represents Eq.(5); the vertical bar in Fig. 3 represents the standard deviation for a single value of the dependent variable, the vapor pressure.

There is no temperature dependence in Eq. (2) because it was based on the release of storedfission gas during water-vapor, injection tests in experiment HRB-17 at essentially constant temperature $\left(770 \pm 13^{\circ} \mathrm{C}\right)$.

"The data must be normalized to display the dependence of fission-gas release on water-vapor pressure. The temperature of normalization was chosen to be $770^{\circ} \mathrm{C}$ for this purpose and also to permit comparison of the results of experiments HFR-B1 and HRB-17 (see section 3.1.4). 
ORNL-DWG 91-13440

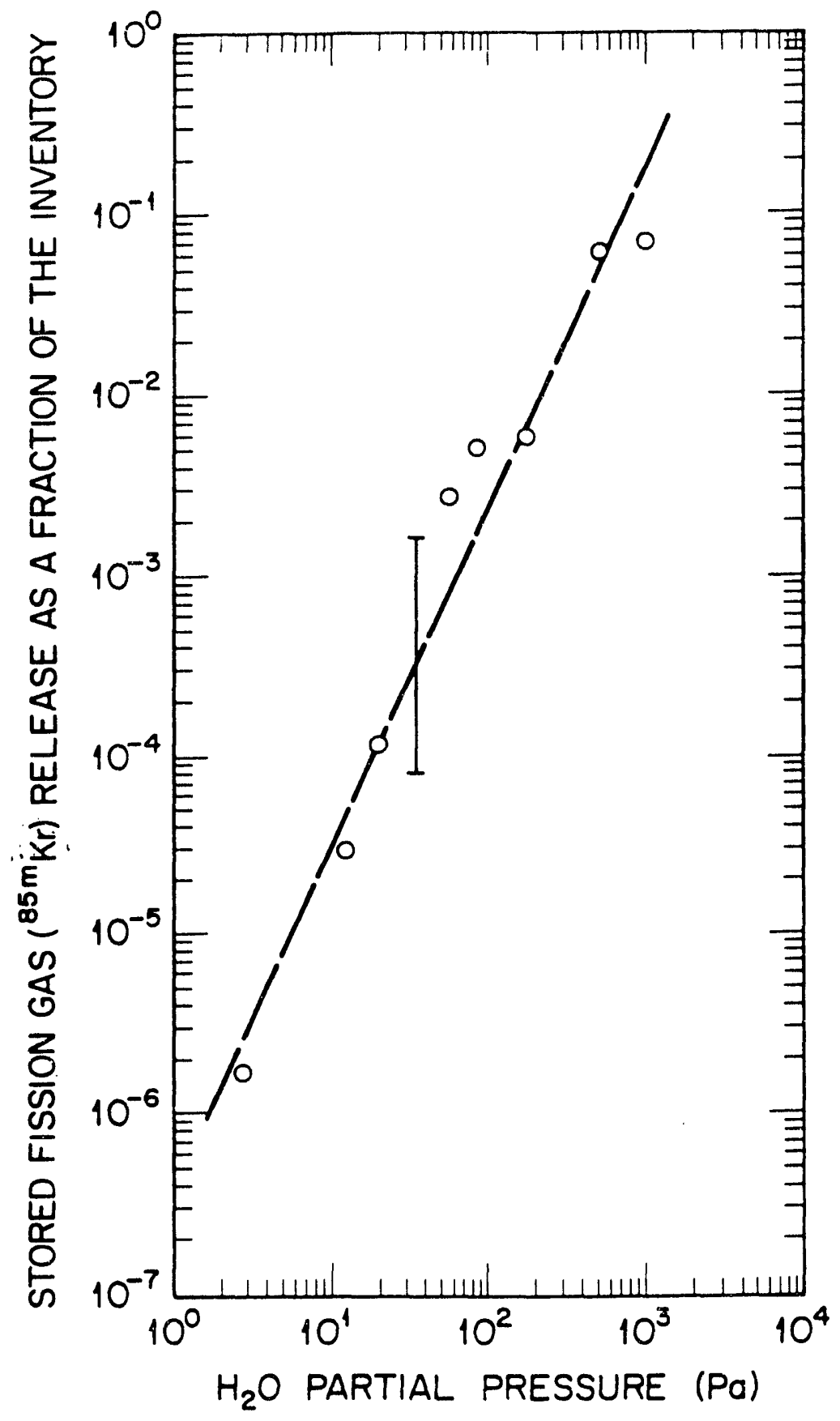

Fig. 3. The dependence of the release of stored-fission gas on the partial pressure of water vapor at $770^{\circ} \mathrm{C}$ derived from experiment HFR-B1. 
A comparison of the measurements and calculations at the experimental temperatures in HFR-B1 is shown in Fig. 4. The values of $f$ from Table 1 have been plotted against the values of $\mathrm{P}_{H 2 \mathrm{O}}$, the water-vapor pressure at the fucl compact surfaces. The line segments in Fig. 4 are calculated by using Eq. (5) for the corresponding temperatures; local segments illustrate the slope of the function. The fractional standard deviation is 0.48 for all data except the one at $820^{\circ} \mathrm{C}$; including the latter in the calculation increases the fractional standard deviation to 0.93 . The deviance of the datum at $820^{\circ} \mathrm{C}$ is greater than the standard deviation of the average value of the independent variable but less than the standard deviation for a single value of the independent variable. The attribution of the deviance of the datum at $820^{\circ} \mathrm{C}$ remains to be establiched.

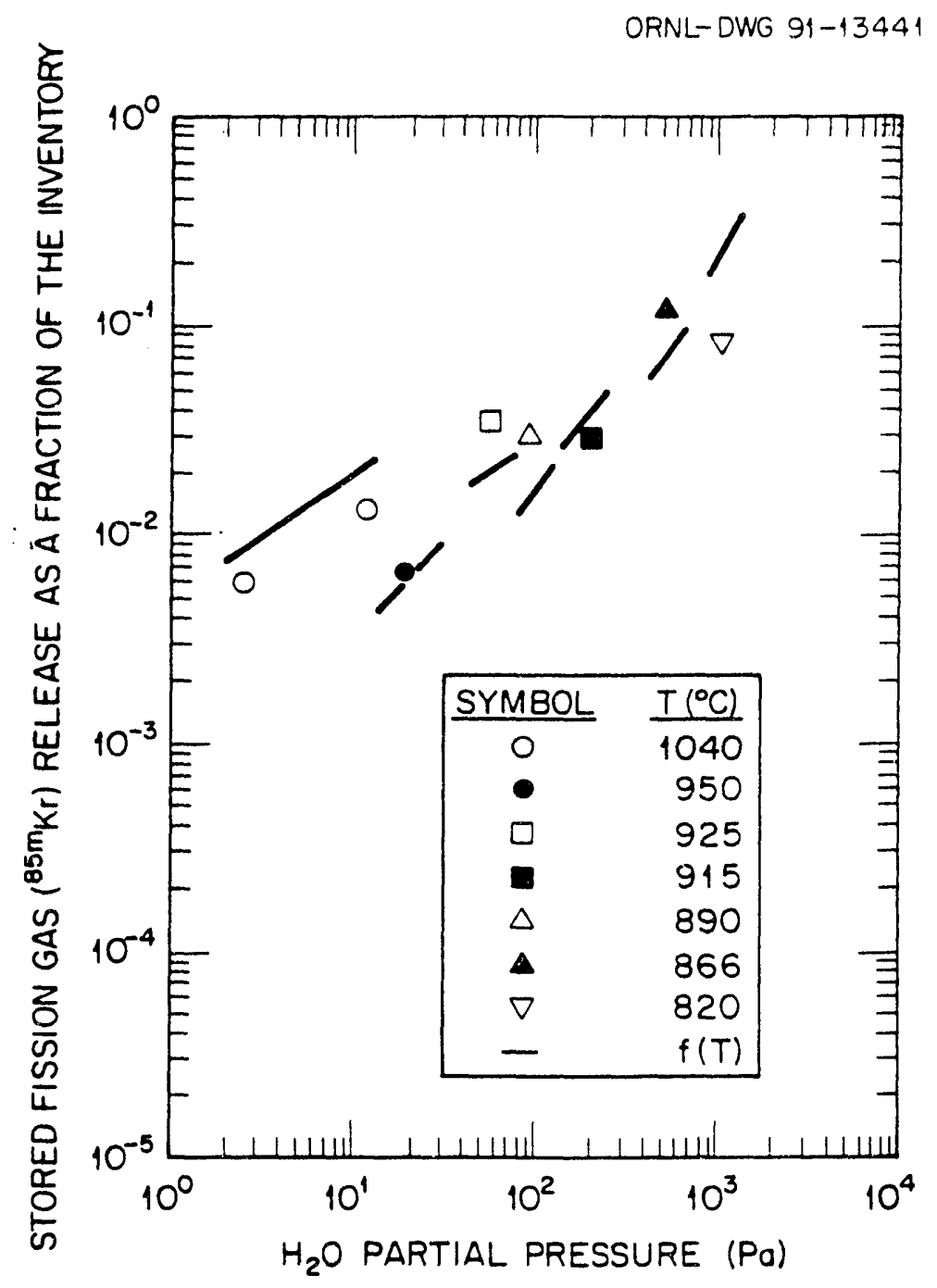

Fig. 4. Comparison of calculations and measurements at the temperatures of the watervapor injection tests in HFR-B1. 


\subsubsection{Comparison of the release of stored-fission gas in the HFR-B1 and HRB-17 experiments}

The comparison of the data from HFR-B 1 with corresponding data at $770^{\circ} \mathrm{C}$ from $\mathrm{HRB}-17$ is shown in Fig. 5. The slopes of the fitted lines through both sets of data are the same as a result of applying the consistency criterion. However, the data from HFR-B1 lie below those from

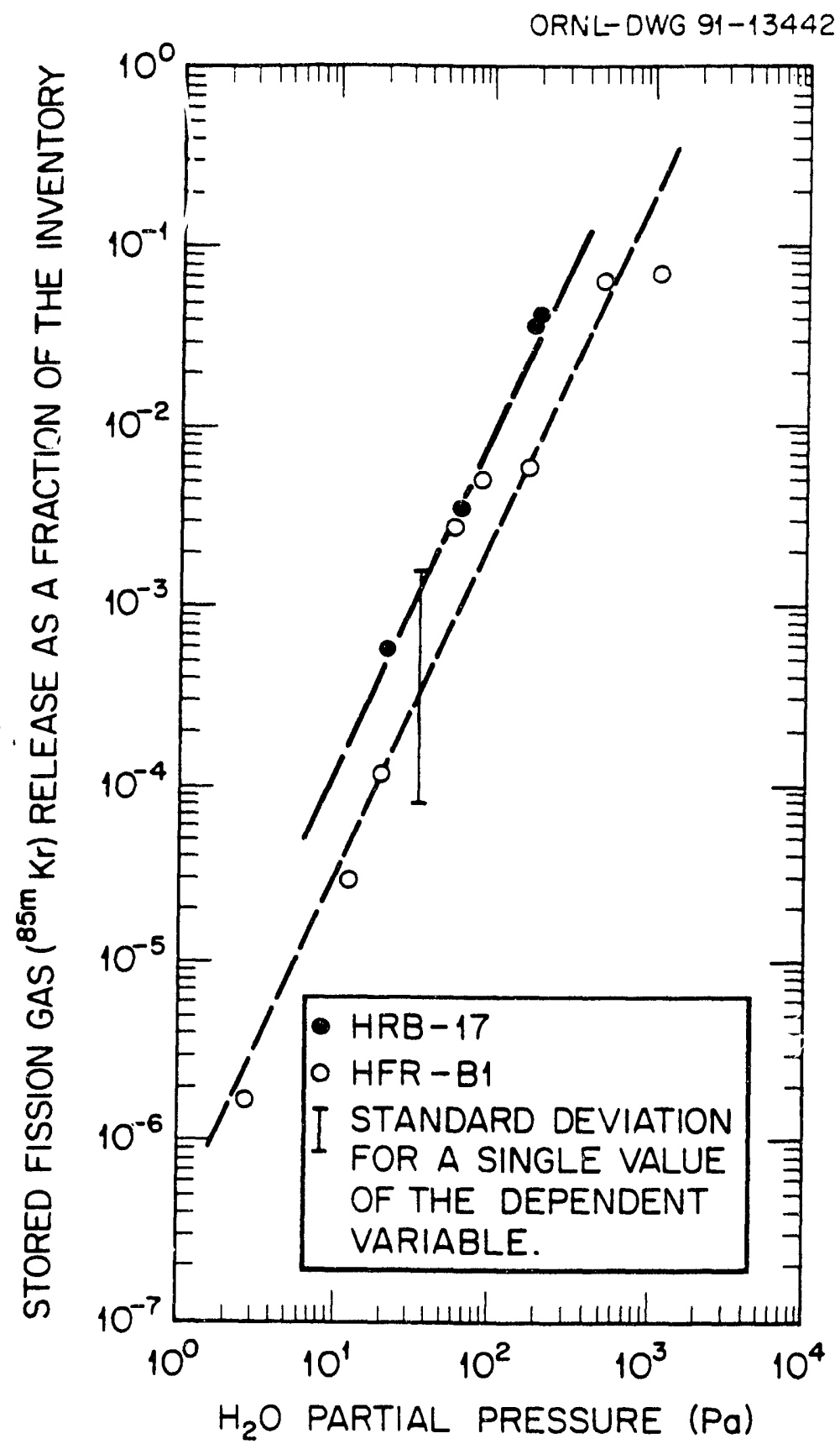

Fig. 5. The dependencies of the release of stored fission gas on the partial pressure of water vapor at $770^{\circ} \mathrm{C}$ derived from experiments HFR-B1 and HRB-17. 
HRB- 17 by a factor of about 4. This dilference is not significant at one standard deviation for a single value, as well as, for the average value of the dependent variable. However, the possibility exists that the difference would be significant if much larger populations of data had been generated in the HRB-17 and HFR-B1 experiments. In this event, the fission-rate densities and neutron fluxes, smaller in the HFR-B1 than in the HRB-17 experiment. would become of interest. From the analysis of the HRB-17 experiment, it can be estimated that the fission-rate density differences in these two experiments could not account for more than a factor of two difference in the release of stored-fission gas as a fraction of the inventory. Likewise, the differences in the neutron flux, being a factor of three, could also not account fully for the differences in the release. Nevertheless, the effects of the fission-rate density and the neutron flux, singly or in combination, might reduce the differences in release to a degree sufficient to render the residual differences negligible were the statistics adequate. In planned efforts to fully analyze all the data from HFR-B1, the possible effects of the fission-rate density and the neutron flux will be thoroughly examined.

Concerning the accuracy of the calculation of the partial pressure of water vapor, to which reference was made in Section 3.1.2, comparison of the data in Fig. 5 indicates that the calculation is unlikely to be in error by more than a factor of 2 provided the data from experiment HRB-17 are accepted as accurate.

\subsubsection{Isorelease curves}

The isorelease curves shown in Fig. 6 were derived from Eq. (5). On these curves, the release of stored-fission gas as a fraction of the inventory is constant at the values shown. Each point on the

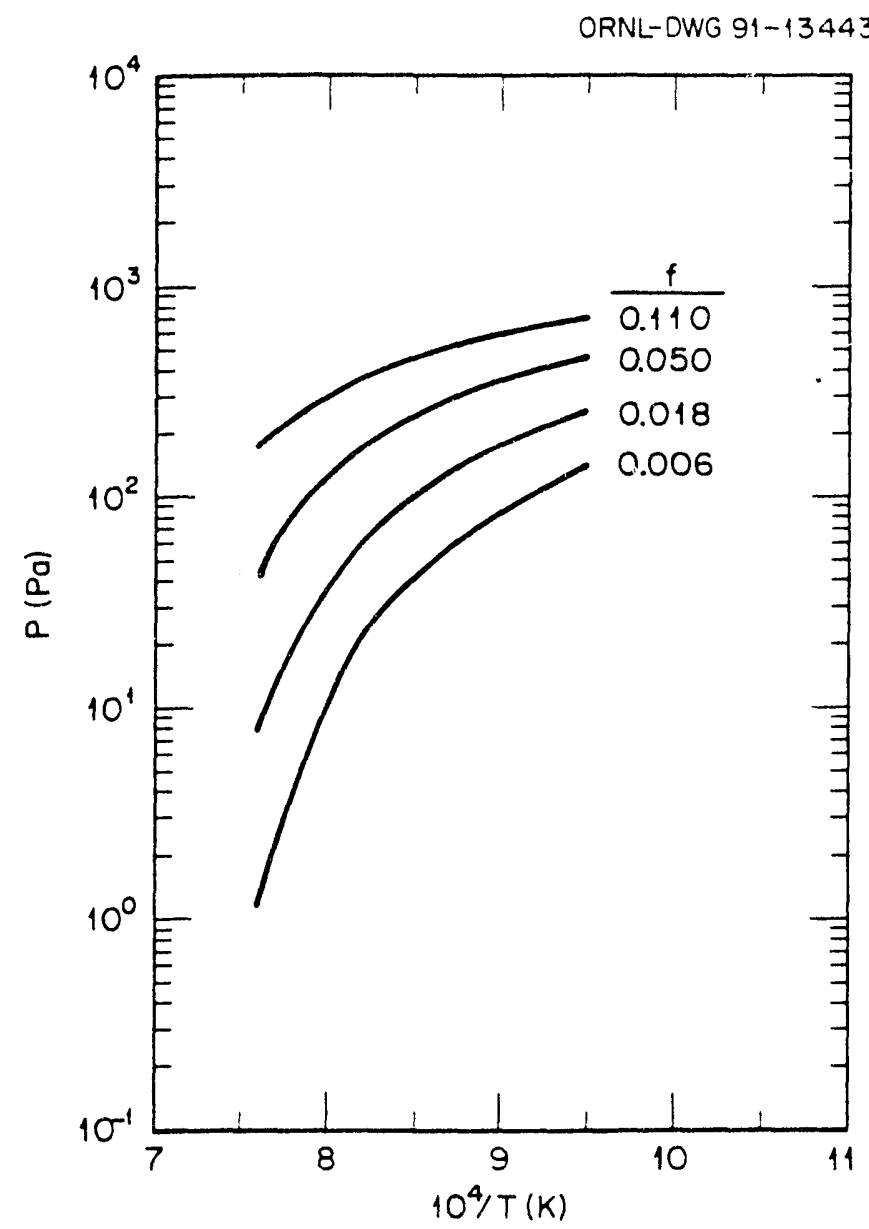

Fig. 6. Isorelease curves on the pressure-temperature plane for stored-fission gas. 
curve represents a pair of values (P.T) and for all the pairs represented by each curve, the relcase of stored-fission gas is the same. The curves are shown over the limited ranges of pressure and temperature to which the experiments were restricted; extrapolation beyond these ranges is not justified (see Appendix B). Another restriction applies; the curves apply only for the range of fissionrate densities and neutron fluxes of experiments HRB-17 and HFR-B1. If the dependence of release on the latter two variables were known, the constancy of release might have to be represented by points on a surface or hypersurface with variables $P, T$, and $F$, or $\phi$ or $F$ and $\phi, F$ being the fissionrate density and $\phi$ the neutron flux.

\subsection{DIFFUSIVE RELEASE OF FISSION GAS}

Following the completion of the release of stored-fission gas, the release becomes steady as illustrated in Fig. 1. This behavior was first noted in experiment HRB-17 (Myers, 1992). As a measure of the magnitude of this release, the ratio

$$
H_{c}=(R / B)_{\text {plateau }} /(R / B)_{\text {prehydrotrysis }}
$$

was adopted (Myers, 1992). R/B represents the steady-state, fractional, fission-gas release, i.e., the ratio of the release rate, $R$, to the birth rate, $B$, for a specific isotope. The region of steady release following the completion of the reiease of stored fission gas was termed the plateau region and the region immediately prior to water vapor addition, the prehydrolysis region. The definition of Eq. (6) includes the following condition: $(\mathrm{R} / \mathrm{B})_{\text {prehydroyss }}$ is to represent release from a fuel in the absence of water vapor and in which no effects on release of any previous exposure to water vapor remain. If this condition is not satisfied or has not been deternined to be satisfied, the ratio will be represented by the symbol $H_{c}^{\prime}$. The magnitude of the ratio as a function of temperature and water-vapor concentration is examined here.

\subsubsection{The temperature dependence of $(R / B)_{\text {plateau }}$} ...

The temperature dependence of $(\mathrm{R} / \mathrm{B})_{\text {plateau }}$, representing diffusive release, was determined from the data in cycle 89.06 of HFR-B1 during which the temperature was changed from 820 to $870^{\circ} \mathrm{C}$ as shown in Fig. 7. Using the mean values of $R / B$ in the plateau regions at the two temperatures, represented by the line segments touched by the upper arrow heads, an activation energy of 23.6 $\mathrm{kJ} / \mathrm{mol}$ was derived. This value is consistent with previously derived estimates (Myers, 1992) of 27.7 $\mathrm{kJ} / \mathrm{mol}$ for hydrolyzed but sintered fucl. The lower value derived from unsintered fuel is consistent with expectations based on a larger density in sintered than in unsintered fuel.

At this stage, the analysis has lead to the conclusion that the activation energy for the release of stored-fission gas is substantially larger than that for diffusive release. The ratio of activation energies is 16.6. A corollary to this is the need to consider these two mechanisms separately in any analysis of the data.

\subsubsection{The dependence of $\mathrm{H}_{\text {c }}$ on the partial pressure of water vapor}

Previous observations (Myers, 1992) at constant temperature have shown that $H_{c}$ is independent of the water-vapor pressure over the range of pressures from 20 to $200 \mathrm{~Pa}$. By applying the principle of consistency, a similar independence is expected in the $\mathrm{H}_{s}$ values derived from the HFR-Bl experiment.

The values of $\mathrm{H}_{\mathrm{c}}{ }^{\prime}$ [see text following Eq. (6)] for ${ }^{85 \mathrm{~m}} \mathrm{Kr}$ derived from HFR-B1 are shown in Table 2 for water vapor pressures in the range 3 to $184 \mathrm{~Pa}$; these are comparable with those on the 


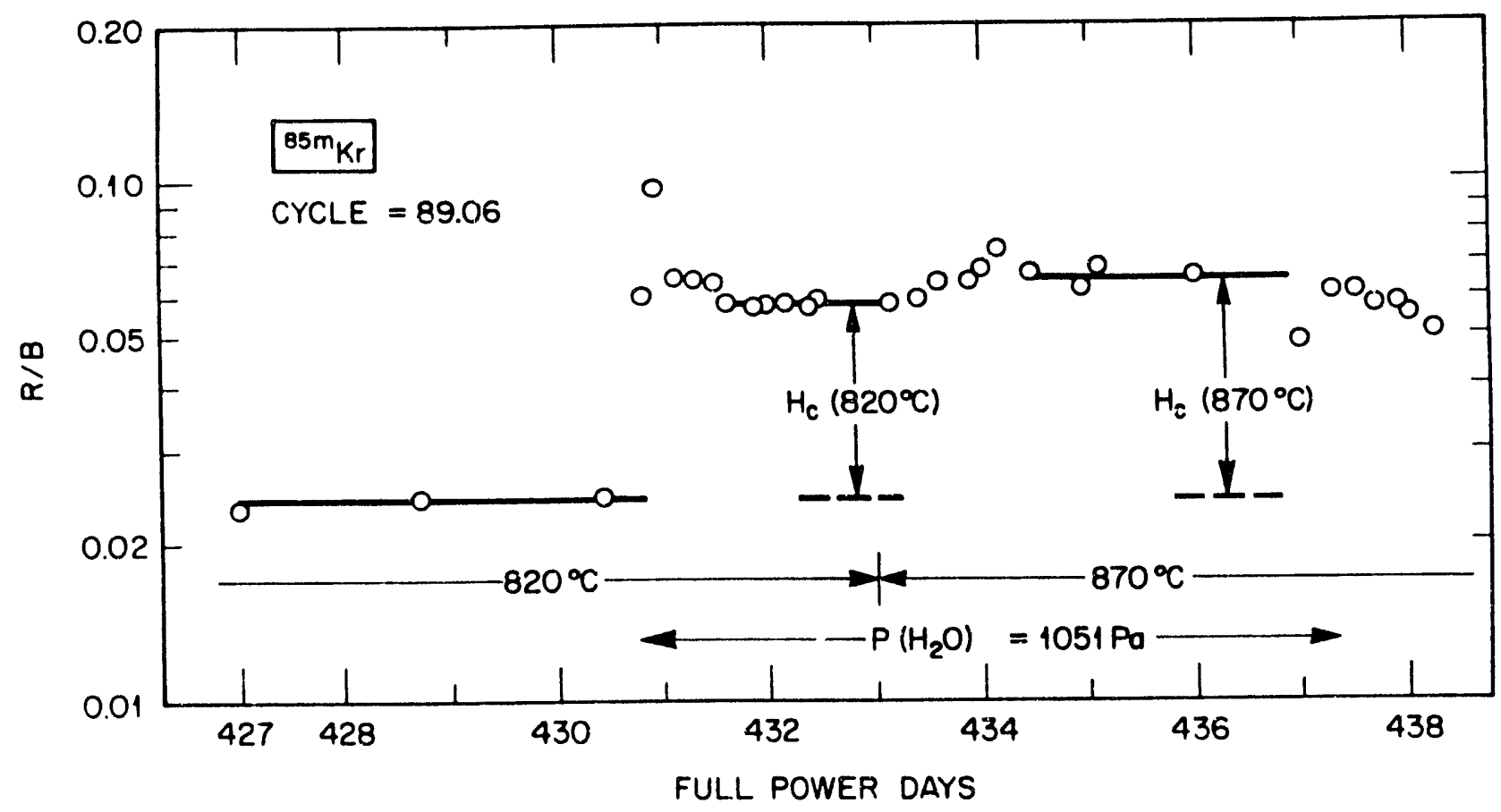

Fig. 7. The ratio $H_{c}$ of the steady-state, fractional fission gas release in the plateau and prehydrolysis regions at 820 and $870^{\circ} \mathrm{C} ; \mathrm{H}_{\mathrm{c}}=(\mathrm{R} / \mathrm{B})_{\text {ptecend }} /(\mathrm{R} / \mathrm{B})_{\text {prtidytatyer. }}$

previous experiments (Myers, 1992). Clearly, the values are not constant as expected. If the effect of temperature on $\mathrm{H}_{c}{ }^{\prime}$ is taken into account, the values of $\mathrm{H}_{c}^{\prime}$ still vary as shown in Table 2; here

$$
H_{c}{ }^{\prime}\left(T_{m}\right)=H_{c}{ }^{\prime}(T) \cdot\left\{\exp \left(-Q / R T_{m}\right)\right\} /\{\exp (-Q / R T)\}
$$

where

$$
\begin{aligned}
\mathrm{T}_{\mathrm{m}}= & \text { the mean temperature }\left(915^{\circ} \mathrm{C}\right) \text { of the water-vapor injection tests in HFR-B1 } \\
& \text { and the temperature to which values of } \mathrm{H}_{\mathrm{c}}{ }^{\prime} \text { have been normalized using Eq. (7) } \\
& \text { and, } \\
\mathrm{Q}= & \text { the activation energy }(23.6 \mathrm{~kJ} / \mathrm{mol}) \text { for the temperature dependence of } \mathrm{H}_{\mathrm{c}}{ }^{\prime} \text { (sce } \\
& \text { Sections } 3.2 \text { and } 3.2 .1) .
\end{aligned}
$$

However, as will now be shown, a major contribution to the apparent variability lies in the release behavior after the cessation of the water-vapor injection [event 3 in the terminology introduced above; see the introduction and Fig. (8)]. 


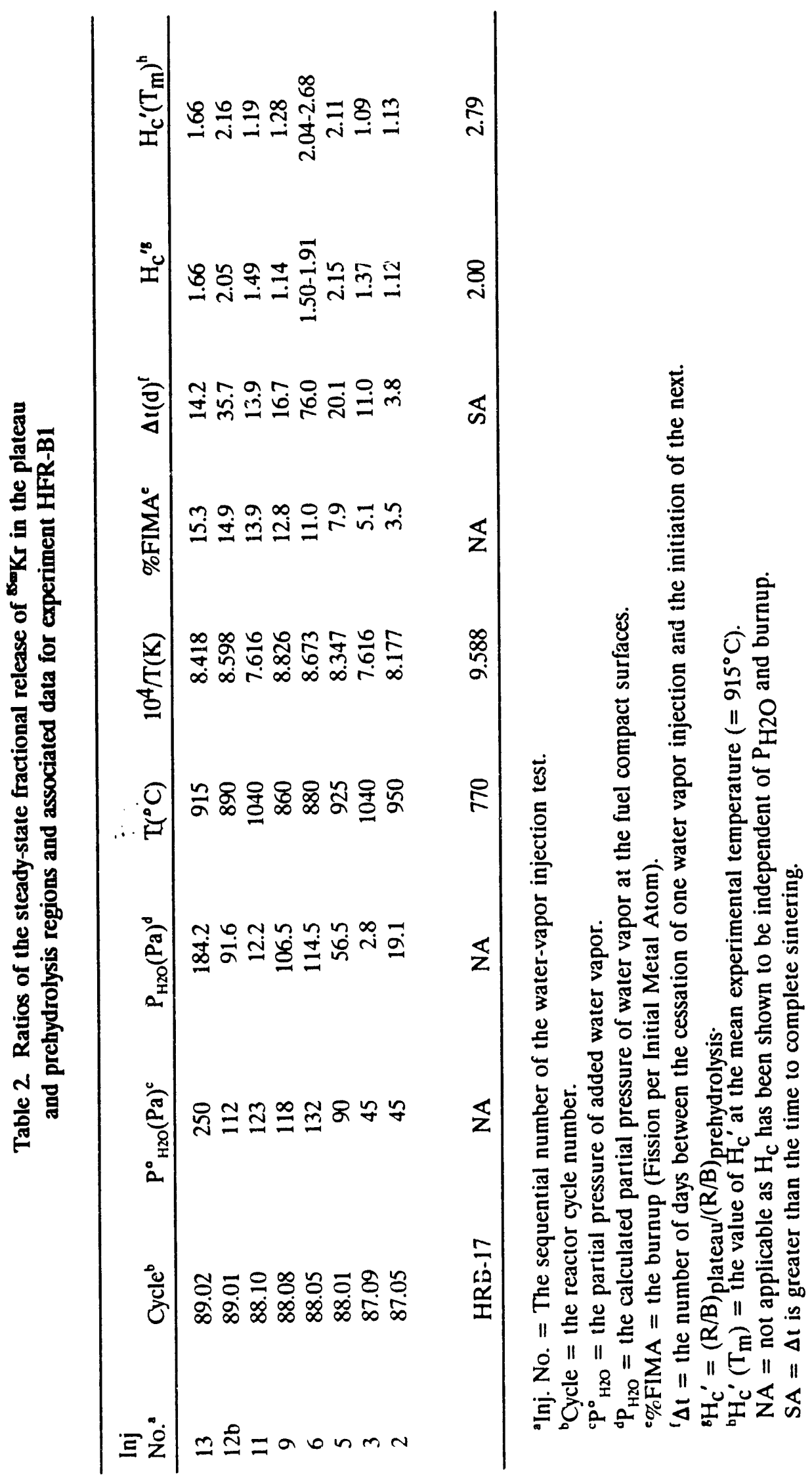




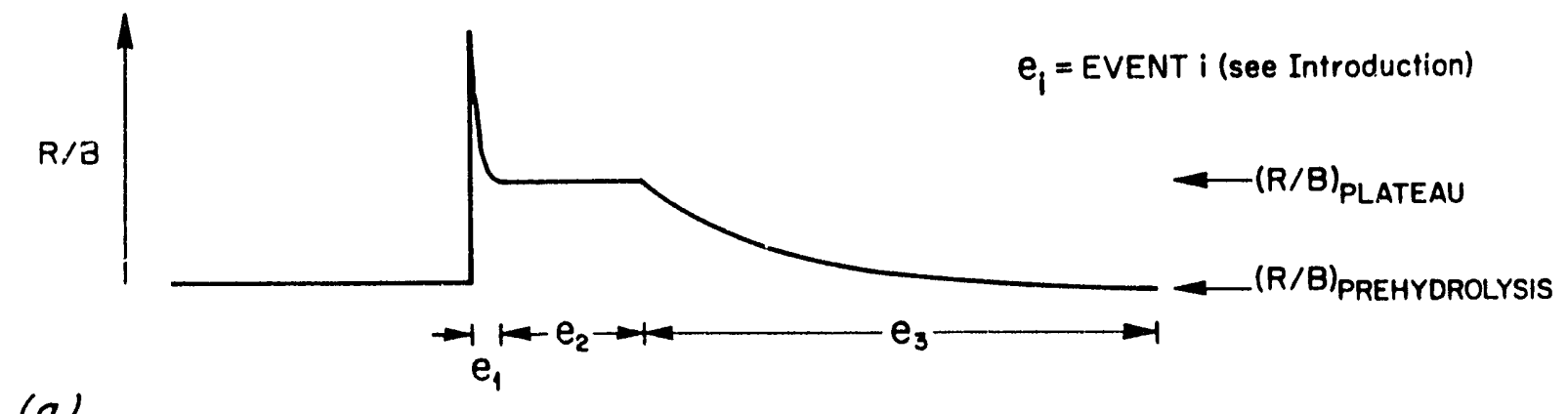

(a)

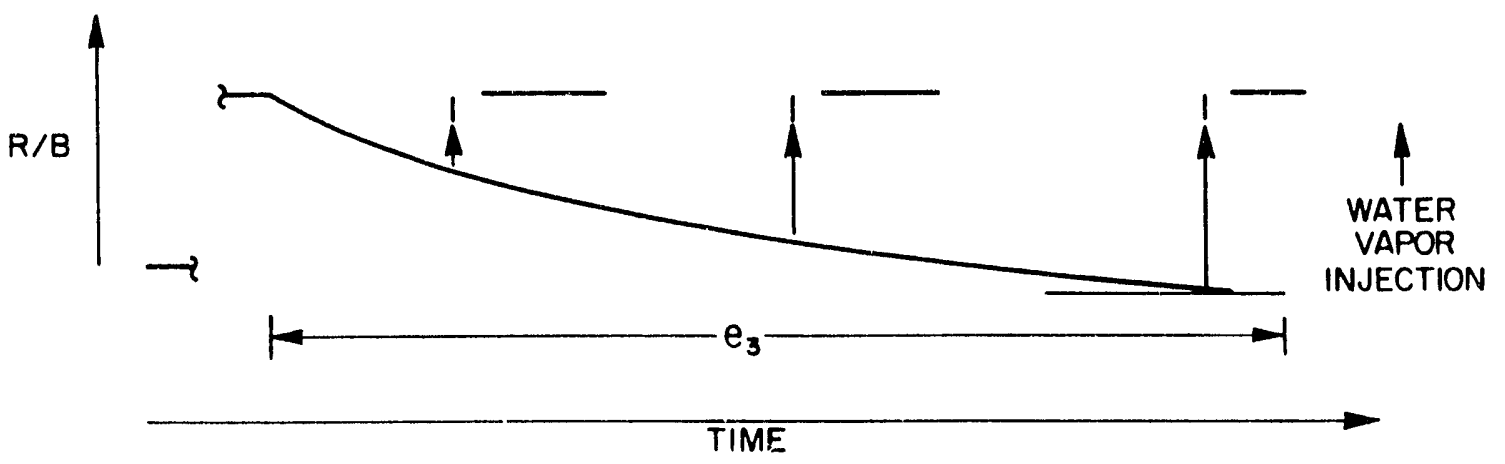

(b)

Fig. 8. The effect of adding water vapor to a test sample containing exposed fucl before sintering is complete.

After the cessation of water-vapor injection, $R / B$ declines slowly and, in the general case, returns to the prehydrolysis value, Fig. (8a). This had been observed in the HRB-17 experiment (Myers, 1992). The decline was also observed in the HFR-B1 experiment. Now consider the possibility that a subsequent water-vapor injection begins before the decline is complete; a schematic diagram of this possibility is shown in Fig. (8b). If $\mathrm{H}_{\mathrm{c}}$ is truly independent of the partial pressure of water vapor, then the subsequent water-vapor injection will result in a value of $(R / B)_{\text {plateau }}$ equal to that for the previous water-vapor, injection test. In Fig. (8b), subsequent injections at three different times imply that the ratio of $(R / B)_{\text {plateau }}$ to the $(R / B)$ just prior to one of the indicated water-vapor injections will be an increasing function of the time elapsed, $\Delta t$, between the cessation of one water-vapor injection and the initiation of the next.

To demonstrate this, the ratio must be calculated. In Fig. (9), a schematic diagram of two sequential water-vapor, injection tests and definitions of quantities to be used in the demonstration are given. The first water-vapor, injection test is designated $\mathrm{T}$ and the second, $\mathrm{B}$; the injection in the 


$$
1-T=T\left(t<t_{T}\right)-1
$$
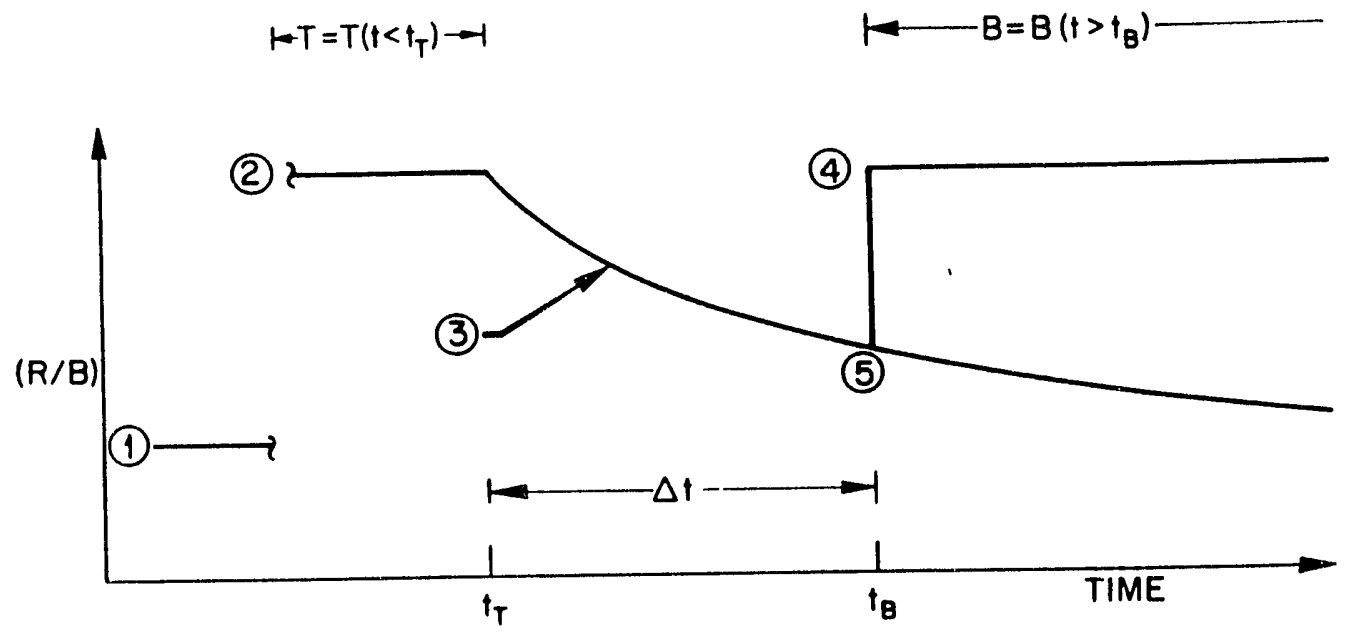
(1) $(R / B)_{T, \text { PREHYDROLYSIS }}$
(5) $(R / B)_{B, \text { PREHYDROLYSIS }} \equiv(R / B)_{4 B, D E C L I N E}$
(2) $(R / B)_{T, P L A T E A U}$
$H_{C}=(R / B)_{T, \text { PLATEAU }} /(R / B)_{T, \text { PREHYDROLYSIS }}$
(3) $(R / B)_{D E C L I N E}$
$H_{c}{ }^{\prime}=(R / B)_{B, P L A T E A U} /(R / B)_{4 B, D E C L I N E}$

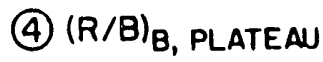
$f_{1}=$ TIME AT WHICH WATER VAPOR INJECTION TERMINATES $(i=T)$ OR BEGINS $(i=\theta)$

Fig. 9. Schematic diagram of sequential water-vapor injection tests and definitions of related quantities.

former test terminates at $t_{T}$ and in the latter begins at $t_{B}$. Four special locations are indicated. The quantities $H_{c}$ and $H_{c}{ }^{\prime}$ are given by the ratio of the $R / B$ values at locations 2 and 1 and 4 and 5 , respectively; the quantity $(R / B)_{B \text {,prehydroysis }}$ is given by the $R / B$ at location 5 . The curve, labeled 3 , represents values of $(R / B)_{\text {decline; }}$ at location $5,(R / B)_{\text {decline }}=(R / B)_{B \text {.prehydroysis. }}$

To quantitatively describe the dependence of $H_{c}{ }^{\prime}$ on $\Delta t$, consider the ratio of $(R / B)$ during the decline, event 3 , to that in the prehydrolysis region (Myers, 1992),

$$
\begin{aligned}
& (\mathrm{R} / \mathrm{B})_{\text {decline }}(\mathrm{R} / \mathrm{B})_{\mathrm{T} \text {,prehydrolysis }}=\mathrm{c}_{\mathrm{f}}+\left(\mathrm{H}_{\mathrm{c}}-\mathrm{c}_{\mathrm{f}}\right) \exp \left\{-\delta\left(\mathrm{t}-\mathrm{t}_{\mathrm{T}}\right)\right\} \\
& H_{c}=H_{c}(T)=h_{o} c_{f}
\end{aligned}
$$

and

$$
\delta=8(\mathrm{~T}, \mathrm{~F}, \phi)
$$


where

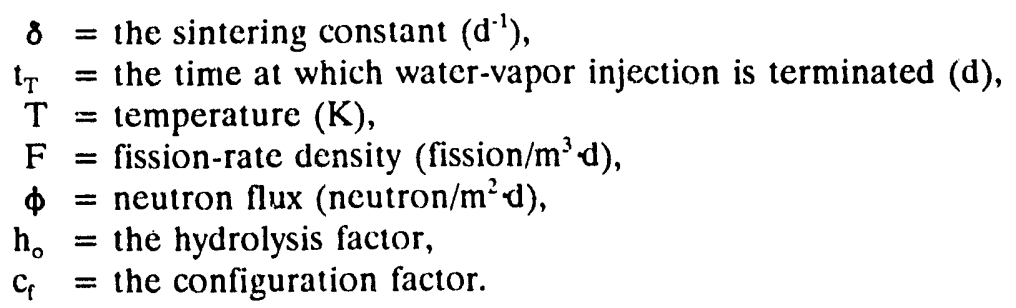

At $\mathrm{t}=\mathrm{t}_{\mathrm{T}}$,

$$
(R / B)_{\text {declind }} /(R / B)_{\text {T.prehydrolysis }}=(R / B)_{\text {plateau }} /(R / B)_{\text {T.prehydrolysis }}=H_{c}
$$

Then, if $c_{\mathrm{f}}=1$,

$$
\mathrm{H}_{\mathrm{c}}{ }^{\prime}=\mathrm{H}_{\mathrm{c}}\left\{\left[1+\left(\mathrm{H}_{\mathrm{c}}-1\right) \exp \left\{-8\left(\mathrm{t}-\mathrm{t}_{\mathrm{T}}\right)\right\}\right]\right.
$$

where $H_{c}{ }^{\prime}$ is the ratio of $R / B$ in the plateau to the prehydrolysis region at any time $t_{B}$. Note that $H_{c}{ }^{\prime}$, as defined in Eq. (10), is the ratio of $(R / B)_{\text {plateau }}$ to (R/B) decline according to Eqs. (8) and (9). At $t=t_{B}$,

$$
H_{c}^{\prime}\left(t, t_{T}\right)-H_{c}{ }^{\prime}\left(t_{B}, t_{T}\right)=H_{c}{ }^{\prime}(\Delta t)
$$

As $\Delta t$ increases, $H_{c}{ }^{\prime}$ increases and in the limit becomes equal to $H_{c}$. This is in accordance with the development shown in Fig. 8 b.

To evaluate the hypothesis that $\mathrm{H}_{\mathrm{c}}{ }^{\prime}$ is an asymptotic function of $\Delta \mathrm{t}$, the time elapsed between the cessation of one water-vapor injection and the beginning of the next, measured values ${ }^{\prime} \mathrm{H}_{\mathrm{c}}{ }^{\prime}$ will be compared with values calculated according to Eq. (10). This requires values of $H_{c}$ and 8 .

The value of $\delta$ is determined by using a derivative of Eq. (8) with $c_{f}=1$. Thus,

$$
\partial \ln H / \partial t=-8
$$

where

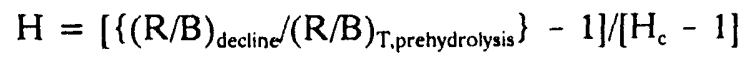

The result of applying Eq. (12) is shown in Fig. 10 for the decline following water vapor injection number 5. This test is unique in that $76 \mathrm{~d}$ elapsed between cessation of the water-vapor injection and the beginning of water- vapor injection in the next test; thus, the complete decline curve was observed. Note that the decline in $\mathrm{R} / \mathrm{B}$ is $95 \%$ complete after $27.5 \mathrm{~d}$. The temperature during the decline was $925^{\circ} \mathrm{C}, 8=0.109 / \mathrm{d}$ and $\mathrm{H}_{c}=2.30$. The latter is a value corrected for the incomplete decline in $\mathrm{K} / \mathrm{B}$ preceding the start of the water-vapor injection in test 5 ; the corrected value is based on the constant values of $(R / B)_{\text {decline }}$ for test 5 reached between 25 and $35 \mathrm{~d}$ after the cessation of the water-vapor injection.

To test the hypothesis that $\mathrm{H}_{\mathrm{c}}{ }^{\prime}$ increases asymptotically with $\Delta \mathrm{t}$ (the time elapsed between the cessation of one water-vapor injection and the beginning of the next), the measured values of $H_{c}{ }^{\prime}$ are compared with calculations according to Eq. (10) under the following restrictions: (1) the calculated, as well as, the measured values are derived from experiment HFR-B1 and (2) the range 


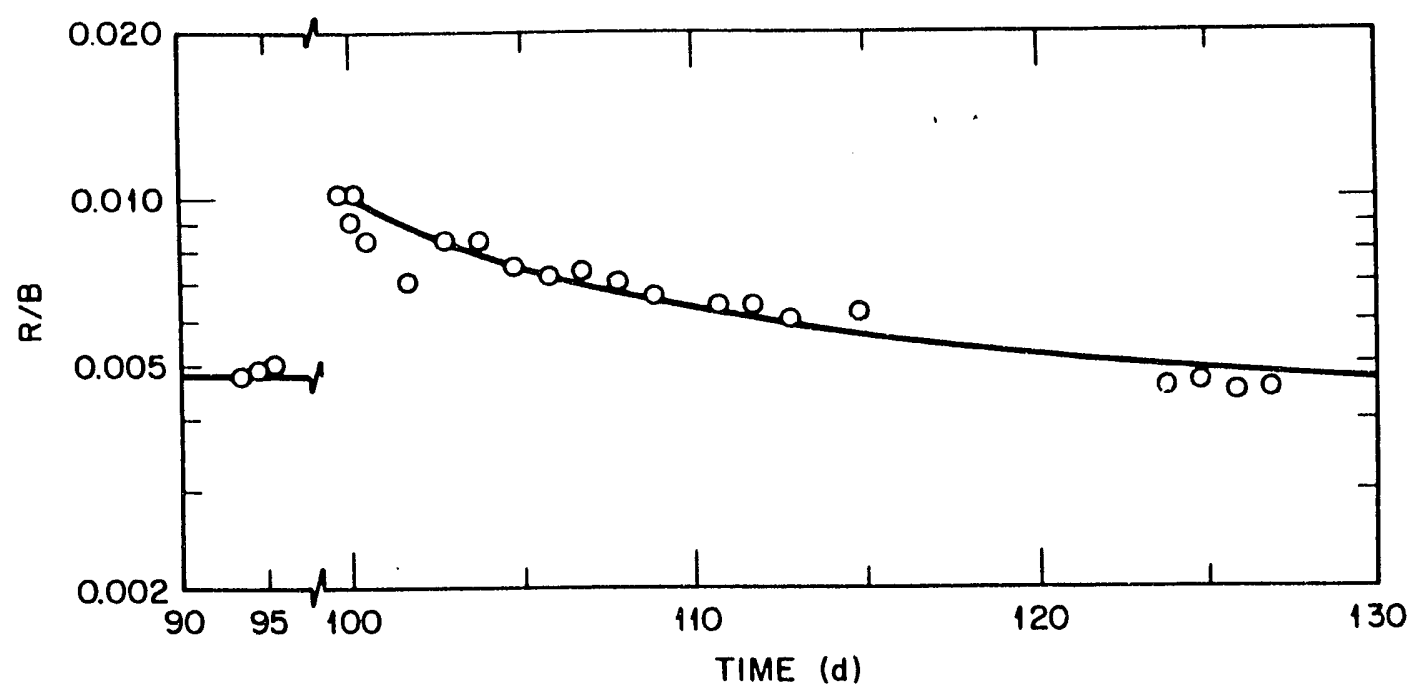

Fig. 10. The decline of R/B following the termination of water-vapor injection in cycle 88.01, test 5 at $925^{\circ} \mathrm{C}$. The symbols represent experimental points and the curve is a fit according to Eq. 8 with $8=0.109 / \mathrm{d}, \mathrm{H}_{\mathrm{c}}=2.30$ and $(\mathrm{R} / \mathrm{B})_{\text {pretydrabyen }}=4.6 \mathrm{E}-3$.

of $\mathrm{P}_{\mathrm{H} 20}$ values ( 3 เo $184 \mathrm{~Pa}$ ) is approximately the same as in experiment HRB-17 (21 to $199 \mathrm{~Pa}$ ) where $\mathrm{H}_{\mathrm{c}}{ }^{\prime}=\mathrm{H}_{\mathrm{c}}$. To simplify the comparison, the measured values of $\mathrm{H}_{\mathrm{c}}{ }^{\prime}$ were normalized to the mean temperature of the injection experiments, $915^{\circ} \mathrm{C}$, and were compared with the calculations using the derived values of 8 and $\mathrm{H}_{c}$ at $925^{\circ} \mathrm{C}$; the differences in the values of these two parameters for $\mathrm{T}=915$ and $925^{\circ} \mathrm{C}$ is small enough to neglect.

The measured values of $\mathrm{H}_{c}{ }^{\prime}$ in experiment HFR-B1 are compared with the calculated values (represented by a curve) in Fig. 11. For five of the data, the agreement is quite good and substantiates the hypothesis. The agreement implies that the variation in $\mathrm{H}_{\mathrm{c}}{ }^{\prime}$ for HFR-B1 is a result of beginning water vapor injection experiments before sintering of the previously hydrolyzed fuel was completed. The remaining three points lie systematically below the calculations and, curiously, have $\mathrm{H}_{c}{ }^{\prime}$ values almost exactly two-thirds of the calculated values.

In summary, the dependence of $H_{c}$ on the partial pressure of water vapor is probably the same in experiments HFR-B1 and HRB-17. This is roughly shown when account is taken of the effects of adding water vapor to HFR-B1/3 before the fuel has completely sintered. This matter will be further examined in the planned full analysis. 


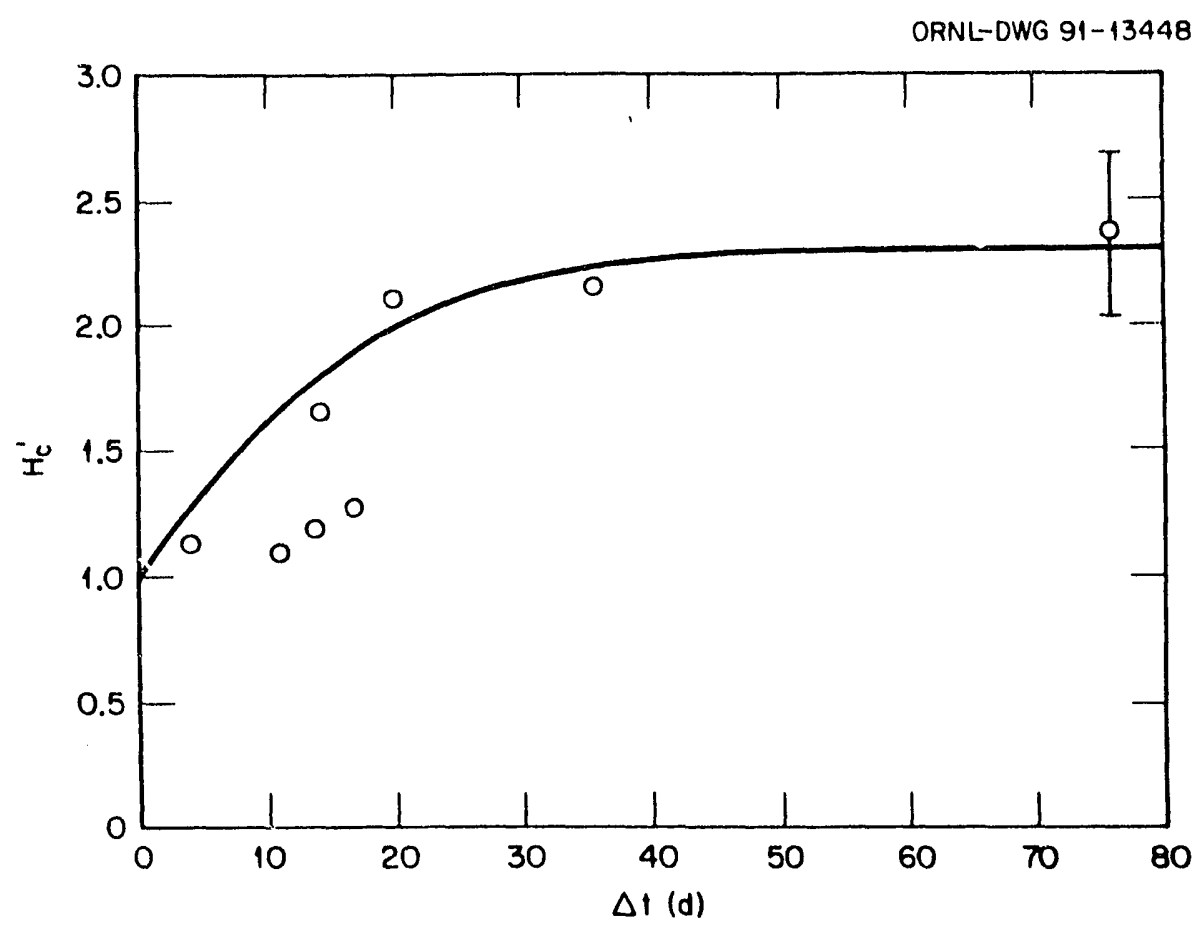

Fig. 11. Comparison of mcasurements of $H_{c}^{\prime}$ with calculations according to Eq. (10).

\section{ACKNOWLEDGMENTS}

Dr. M. B. Richards of General Atomics calculated the reduced water-vapor pressures at the fuel compact surfaces following graphite hydrolysis. Dr. R. P. Wichner provided a penetrating review of the preliminary report. 


\section{REFFRENCES}

Conrad, R., R. D. Burnette and Th. Timke, 1990. "Irradiation of GA-HTGR Fuel Rods at Real Time Simulating Operating Conditions in the HFR Petten," HFR/90/3082, HFR Division, Petten Establishment.

Myers, B. F. and R. E. Morrisscy, 1978. "The Measurement and Modeling of Postirradiation Fission Product Release from HTGR Fuel Particles Under Accident Conditions," GA-A15018, General Atomic Co.

Mycrs, B. F., 1992. "The Effect of Water Vapor on the Release of Fission Gases from Uranium Oxycarbide in High Temperature, Gas Cooled Reactor Coated Fuel Particles" J. Am. Ceram. Soc., 75 686-693

Richards, M. B., 1990. Private communication

Richards, M. B., 1990. "Reaction of Nuclear-Grade Graphite with Low Concentrations of Steam in the Helium Coolant of an MHTGR," Energy, 15 729-39. 


\section{Appendix A \\ DERIVATION OF THE EQUATION DESCRIBING THE RELEASE OF STORED-FISSION GAS AS A FRACTION OF THE INVENTORY}

To determine the relcase of stored-fission gas as a fraction of the kernel inventory for each isotope during a water-vapor injection test, the following relation is defined:

$$
f=\int_{t}^{\prime \prime}\{R(\tau) / I(\tau)\} d \tau
$$

where

$$
\begin{aligned}
& \mathrm{f} \quad=\text { fraction of the inventory released as stored-fission gas, } \\
& \mathrm{t} \quad=\text { time at the beginning of water vapor injection (s) } \\
& \mathrm{t}^{\prime} \quad=\text { time at the end of water vapor injection (s) } \\
& \mathrm{R}(\tau)=\text { a relcase rate difference at time } \tau \text { (atom/s). Sec Eq. (A.4) } \\
& \mathrm{I}(\tau)=\text { inventory at time } \tau \text { (atom). }
\end{aligned}
$$

Experimentally,

$$
R(\tau)=N(\tau) \cdot F_{r}
$$

where

$$
\begin{aligned}
& \mathrm{N}(\tau)=\text { concentration of isotope at } \tau\left(\text { atom } / \mathrm{m}^{3}\right) \text { and } \\
& F_{\mathrm{r}}=\text { flow rate }\left(\mathrm{m}^{3} / \mathrm{s}\right) .
\end{aligned}
$$

Note that $\tau$ is the time at which release from the kernel occurs. The value of $N(\tau)$ is determined from the concentration measured at a sampling station, $N(\tau+\delta t)$, corrected for the decay occurring during the transit time, $8 \mathrm{t}$, bctween release from the kernel and gamma counting of the gas sample at the sampling station. The flow rate is taken to be constant during $8 t$.

In applying Eq. (A.1), values of $R(\tau)$ over small time increments, $R\left(\Delta t_{i}\right)$, are summed so that the working version of Eq. (A.1) is

$$
\mathrm{f}=\Sigma_{\mathrm{i}}\left\{\mathrm{R}\left(\Delta \mathrm{t}_{\mathrm{i}}\right) / \mathrm{I}\left(\Delta \mathrm{t}_{\mathrm{i}}\right)\right\} \Delta \mathrm{t}_{\mathrm{i}}=\Sigma_{\mathrm{i}}\{\mathrm{R} / \mathrm{I}\}_{\mathrm{i}} \cdot \Delta \mathrm{t}_{\mathrm{i}}
$$

assuming average values of $R$ and $I$ over the interval $\Delta t_{i}$.

As contributions to release from stored-fission gas as well as fission gas released diffusively occur concurrently, it is necessary to obtain $\mathrm{R}$ as a difference between these contributions. Thus,

$$
\{R\}_{i}=\left\{R_{s d}\right\}_{i}-\left\{R_{d}\right\}_{i}
$$

where

$R_{s d}=$ release rate of stored plus diffusively released gas and

$R_{d}=$ release rate of diffusively released fission gas.

Since

$$
B\left(\Delta t_{i}\right)=B_{i}=\lambda I\left(\Delta t_{i}\right)=\lambda I_{i}
$$


where

$$
\begin{aligned}
\mathrm{B}\left(\Delta \mathrm{t}_{\mathrm{i}}\right) & =\text { birth rate of the isotope (atom/s) and } \\
\lambda & =\text { decay constant of the isotope }\left(\mathrm{s}^{-1}\right)
\end{aligned}
$$

Eq. (A.3) can be transformed into Eq. (1) (see Section 3.1.1); thus,

$$
\mathrm{f} \quad=\Sigma_{\mathrm{i}}\left[(\mathrm{R} / \mathrm{B})_{s \mathrm{~d}}-(\mathrm{R} / \mathrm{B})_{\mathrm{d}}\right]_{\mathrm{i}} \Delta \mathrm{t}_{\mathrm{i}} \lambda
$$




\section{RESTRICTIONS AND LIMITATIONS ON THE FUNCTIONAL RELATION BETWEEN RELEASE OF STORED-FISSION GAS AND TEMPERATURE AND WATER-VAPOR PRESSURE}

The release of stored-fission gas as a fraction of the inventory is described by the relation:

$$
f=K \cdot P^{n(T)} \cdot e^{-Q / R T}
$$

where

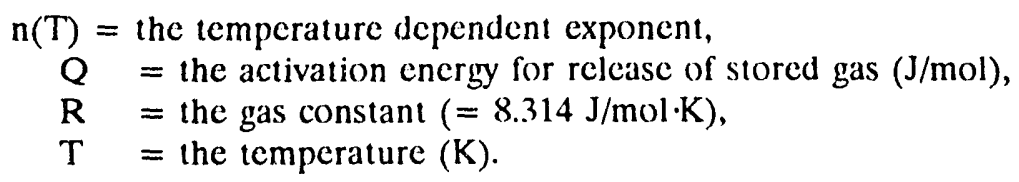

Equation (B.1) is an empirical relation which is meant to describe simply the complicated interplay of the effects of water-vapor pressure and temperature on the release of fission gas from fuel kernels exposed to the water vapor. The simplification is centered in the function $n(T)$ which represents the effective declining relative contribution of water vapor to the release as the temperature incicases (see also Section 3.1.3 above). The actual dependence of the release on water-vapor pressure could perhaps remain constant as the temperature increases and plays an increasingly more important role. In this case, an additive relation with two terms might be appropriate; in the full analysis of these data, surch a relation and perhaps others will be considered.

To understand the limitations of Eq. (B.1), consider a partial derivative of Eq. (B.1):

$$
(\partial \ln \cdot f / \partial \ln P)_{T}=n(T)
$$

Consequently, curves of $\ln \mathrm{f}$ versus $\ln \mathrm{P}$ at different temperatures may cross. For such curves, $f\left(T_{i}\right)=f\left(T_{j}\right)$ and

$$
\ln P_{c}=(Q / R) \cdot\left(T_{i}^{-1}-T_{j}^{-1}\right) /\left\{n\left(T_{i}\right)-n\left(T_{j}\right)\right\}
$$

where

$P_{c}=$ the water-vapor pressure at the crossing point

Because the left hand side of Eq. (B.3) is a function only of the pressure and the right hand side only a function of the temperature, both sides equal a constant; thus,

$$
\left(T_{i}^{-1}-T_{j}^{-1}\right) /\left\{n\left(T_{i}\right)-n\left(T_{j}\right)\right\}=\beta^{-1}
$$

where $B$ is a constant. Thus for all temperatures, the curves of $\ln f$ versus $\ln P$ cross at the watervapor pressure of $P_{c}$. The value of $f_{c}$ depends on the value of $Q$, given a relation for $n(T)$. If one chooses

$$
\mathrm{n}(\mathrm{T})=\alpha+B \mathrm{~T}^{-1}
$$

where $\alpha$ and $B$ are constants, then

$$
\mathrm{f}_{\mathrm{c}}=\mathrm{K} \mathrm{e}^{\alpha \mathrm{Q} / \mathrm{BR}}
$$


and $f_{c}$ is a constant.

The occurrence of a fixed point, $\left(f_{c}, P_{c}\right)$, on the curve of $f$ versus $P$ for all temperatures is unrealistic. Beyond this point, i.c., at larger values of $P$, the release, $f$, would have to become smaller as the temperature increases in contradiction to physical knowledge. Also, unrealistic physical situations would arise if extrapolations to lower values of $P$ outside the range of experimental data are made. Consequently, the application of Eq. (B.1) to the analysis of the release of stored-fission gas must he restricted to the range of the experimental data; conclusions drawn from extrapolations beye d this range are not justified. 

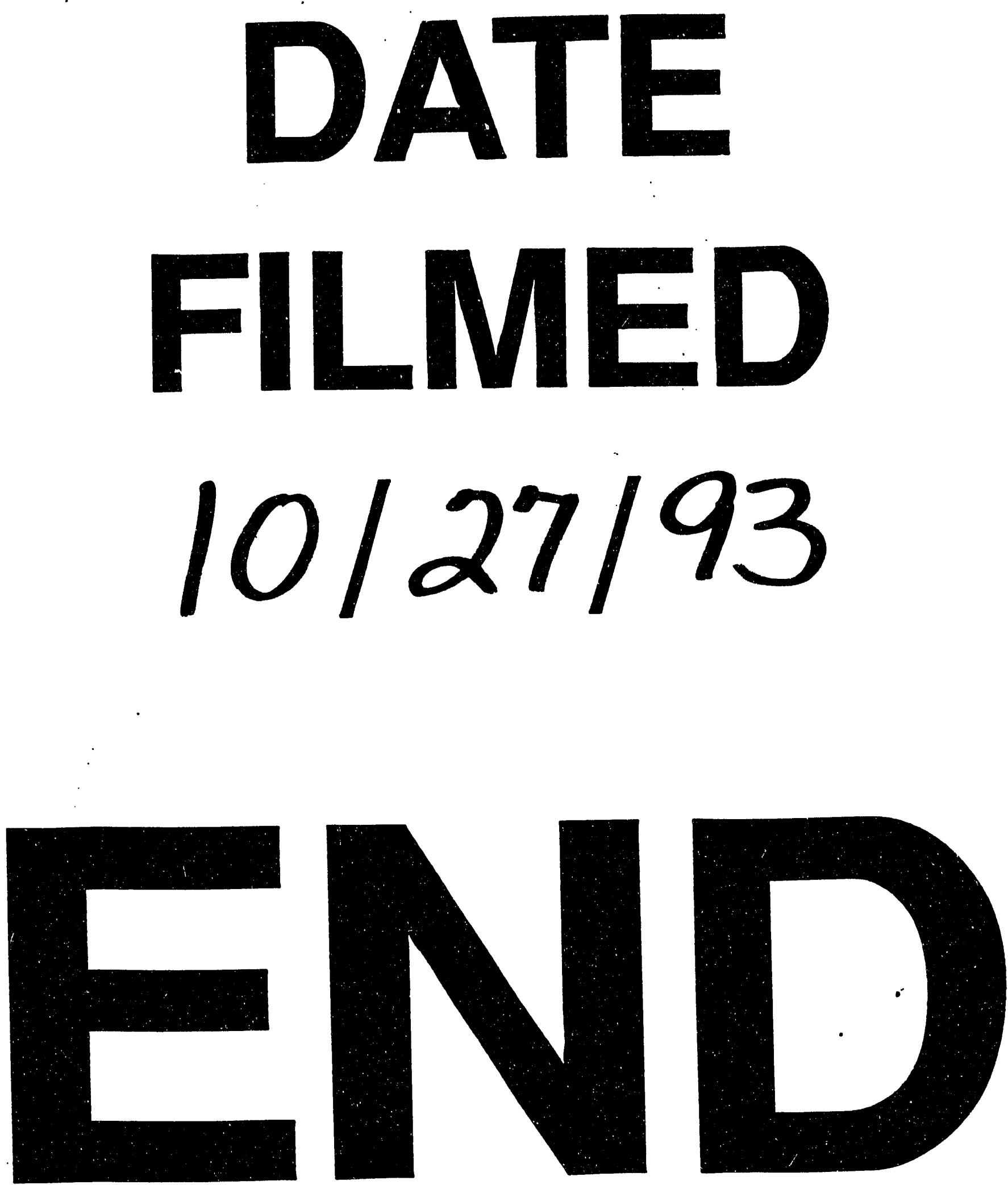
